\title{
Odilon Marc Lannelongue (1840-1911) and strip craniectomy for craniosynostosis
}

\author{
Shyamal C. Bir, M.D., Ph.D., Sudheer Ambekar, M.D., Christina Notarianni, M.D., \\ ANd ANIL NANdA, M.D., M.P.H. \\ Department of Neurosurgery, LSU Health-Shreveport, Louisiana
}

\begin{abstract}
In the 19th century, Dr. Odilon Marc Lannelongue was a pioneering French surgeon who introduced a surgical technique for the treatment of craniosynostosis. In 1890, Dr. Lannelongue performed correction of sagittal synostosis by strip craniectomy. From his procedure, multiple techniques have been developed and endorsed for this condition, ranging from simple suturectomies to extensive calvarial vault remodeling. In addition, even today, endoscopically aided strip craniectomy is performed as a surgical treatment of craniosynostosis. This article describes the life and works of the surgeon who revolutionized the management of craniosynostosis.

(http://thejns.org/doi/abs/10.3171/2014.2.FOCUS13559)
\end{abstract}

Key Words • Odilon Marc Lannelongue - craniosynostosis • craniectomy

\begin{abstract}
$\mathrm{C}$ RANIOSYNOSTOSIS is a congenital defect with premature ossification of 1 or more fibrous sutures, resulting in abnormal head growth and facial dysmorphism. ${ }^{1,19}$ Early closure of a cranial suture restricts the growth of the skull perpendicular to the suture, resulting in abnormal growth and shape of the skull. ${ }^{19}$ There are several types of craniosynostosis depending on the specific suture involved, such as scaphocephaly, brachycephaly, and trigonocephaly. Suboptimal treatment of craniosynostosis may lead to facial dysmorphism, cosmetic deformities, and psychological, cognitive, and developmental sequelae in the long term. Raised intracranial pressure may also develop in as many as $5 \%$ of children. , $^{3,11,20}$ Numerous open and endoscopic techniques have been described for the management of craniosynostosis depending on the suture involved and the age at presentation. Although the understanding of the abnormalities of cranial vault fusion were recognized as early as 16 th century, ${ }^{5}$ it was Dr. Odilon Marc Lannelongue, a French surgeon, who first described the technique of craniectomy for craniosynostosis. ${ }^{12,16}$ Little is known about Dr. Lannelongue and his contribution to science. This paper is an attempt to reflect upon the life and works of the person who changed the lives of many children with craniosynostosis.
\end{abstract}

\section{Biography of Dr. Odilon Marc Lannelongue}

Dr. Lannelongue was born on December 4, 1840, and grew up in Castéra-Verduzan, Gars, France. The son of a physician, he studied medicine in Paris under the supervision of Dr. Charles-Pierre Denonvilliers (1808-1872) and Dr. Auguste Nélaton (1807-1873). In 1867, he completed his thesis on the internal circulation of the heart and received his doctorate degree. In 1869 he became a professor, as well as a surgeon of the Bicêtre Hospital in Paris. He was involved in both surgery and medicine, including the treatment of bone and joint diseases, and neurosurgical congenital malformations such as craniosynostosis. In the latter part of his life, he became a member of several professional societies, including the Académie de Médecine (1886) and the Académie des Sciences (1895). He also became interested in politics, becoming a member of the French Senate (1906). He died in Paris on December 28,1911 , leaving a museum and several foundations that bear his name (Fig. 1). ${ }^{6,12,16}$

\section{Craniectomy for Craniosynostosis}

At the beginning of his appointment in the Bicêtre Hospital, Dr. Lannelongue's work involved disorders of elderly people. However, after joining the staff at the Trosseau Hospital for Children, he gradually became interested in neurological disorders in children. He was the first surgeon to work on congenital malformations of children, including craniosynostosis. ${ }^{12,16}$ In 1890 , he introduced strip craniectomy for sagittal suture synostosis in children 


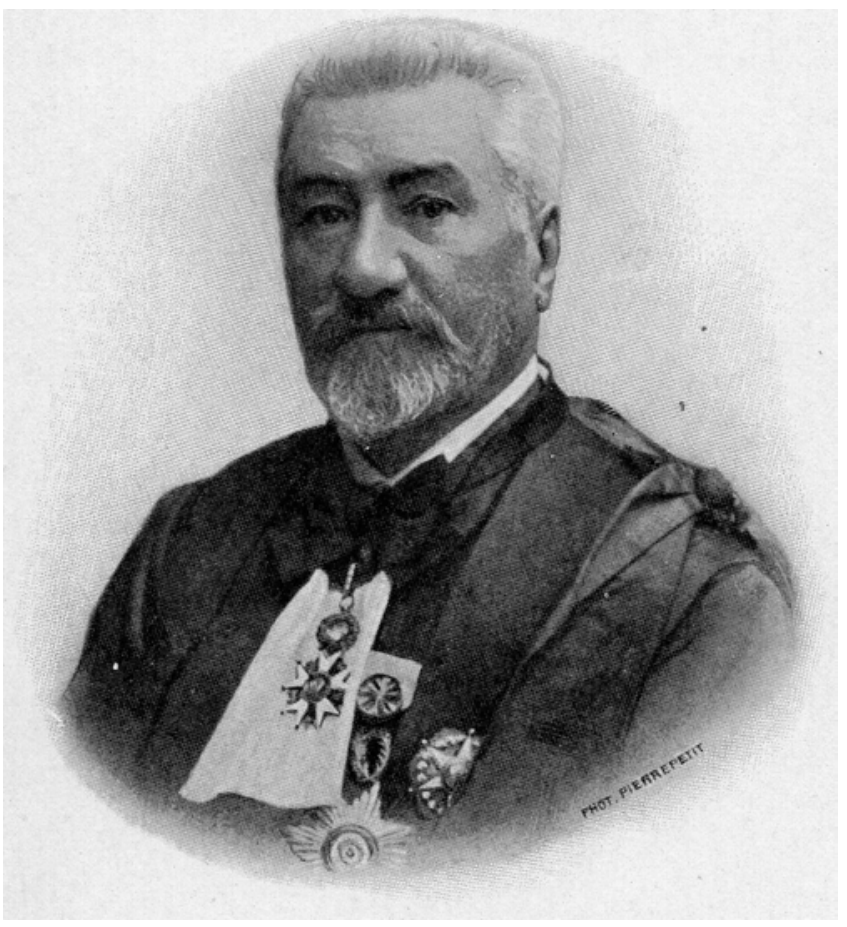

FIG. 1. Dr. Odilon Marc Lannelongue (1840-1911). Source: National Library of Medicine.

with craniosynostosis. This procedure involved two parallel strip craniectomies lateral to the midline, with a strip of bone left over the sagittal sinus. The strip craniectomy continued through the adjacent normal sutures, including the coronal suture anteriorly and the lambdoid suture posteriorly. ${ }^{4,21}$ The procedure was initially proposed as a life-saving surgery to alleviate intracranial pressure. The goal of this operation was also to correct the abnormal head shape and improve microcephaly in those patients, with the idea that the excision of fused sutures would allow for physiological growth of the cranial vault. ${ }^{7}$ Dr. Lannelongue performed strip craniectomies on 59 patients during this time with only 1 death. Surgeries were not easy to perform due to the risk of complications, including blindness, cognitive and neurological damage, and hydrocephalus leading to irreparable brain damage..$^{2,8,13,20}$ This technique of strip craniectomy for craniosynostosis was subsequently adopted by other surgeons, including Dr. L. C. Lane of San Francisco in $1892 .{ }^{14}$ Although there was limited literature on outcome, it appears that the craniectomy procedure for the treatment of craniosynostosis was quickly adopted across the world. Today, modified versions of Dr. Lannelongue's work, such as video-assisted endoscopic strip craniectomy, are widely used for the treatment of craniosynostosis. ${ }^{14}$

\section{Modern Treatment Options Evolved From Dr. Lannelongue's Technique}

Surgical correction of craniosynostosis is primarily performed for cosmetic reasons, but also because $5 \%$ of patients may experience raised intracranial pressure if the fusion (craniosynostosis) is not treated. ${ }^{8,20}$ Since Dr. Lan- nelongue introduced the craniectomy for craniosynostosis in 1890, multiple procedures for this malformation have been developed and adopted, ranging from simpler suturectomies to complex calvarial vault remodeling. . $^{2,4,10,13,17}$ In the traditional open reconstruction, a long incision is made from one ear to the other ear. Craniotomies are then performed to excise the fused suture and the cranial vault is repositioned to allow for its growth. While open correction produces excellent results, blood loss and a long surgical duration may lead to complications in the child..$^{15,22}$ More recently, newer endoscopic minimally invasive techniques have been described for the treatment of craniosynostosis with the aim to minimize blood loss during surgery. ${ }^{18}$ Jimenez and Barone first described the endoscopically assisted craniectomy for craniosynostosis in 1998. ${ }^{9}$ Since then, this technique has been refined and widely adopted in multiple craniofacial centers throughout the world. In endoscopic craniectomy, the operation is performed by small incisions in the skin and endoscopes are used to expose the different areas of the affected suture and perform cranial vault remodeling., ${ }^{9,15}$ While the endoscopic techniques allow less blood loss, they are suited for infants. It is indeed interesting to note how the strip craniectomy first described by Lannelongue has evolved into the present-day techniques of cranial vault remodeling.

\section{Contribution in Medicine}

In addition to his contribution to cranial surgery, Dr. Lannelongue was a follower of Pasteur and recognized that microbial infections are involved in necrosis. He classified necrosis under osteomyelytic, tuberculus, and syphilitic conditions. He is remembered for his work with bone diseases including osteomyelitis, bony tubercular disease, and Osgood-Schlatter disease. He is also credited with introducing the use of zinc chloride to treat synovial tuberculosis..$^{12,16}$

A well-published author, Dr. Lannelongue published a book about congenital cysts in collaboration with his favorite disciple, Dr. Émile Achard. He also authored a book on congenital malformations of the head and neck in 1891 in collaboration with Dr. Victor Menard (Fig. 2). Dr. Lannelongue made several other contributions to the medical literature including papers on osteomyelitis and syphilis. In addition, he published his memoirs on craniectomy for microcephaly. In the latter part of his life, he made a voyage around the world and shared his experience by publishing a book titled Le Tour du Monde (Fig. 3).12,16

\section{Awards and Honors}

Dr. Lannelongue received numerous awards and honors during his career. He was selected for membership in the Académie de Médecine in 1886 and the Académie des Sciences in 1895. In 1892, he was selected as the president of the General Association of Physicians of France (AGMF). He was also appointed president of the International Congress of Medicine in 1900 and president of the International Congress of Tuberculosis in 1905. He also served as president of the French Society of Surgery 


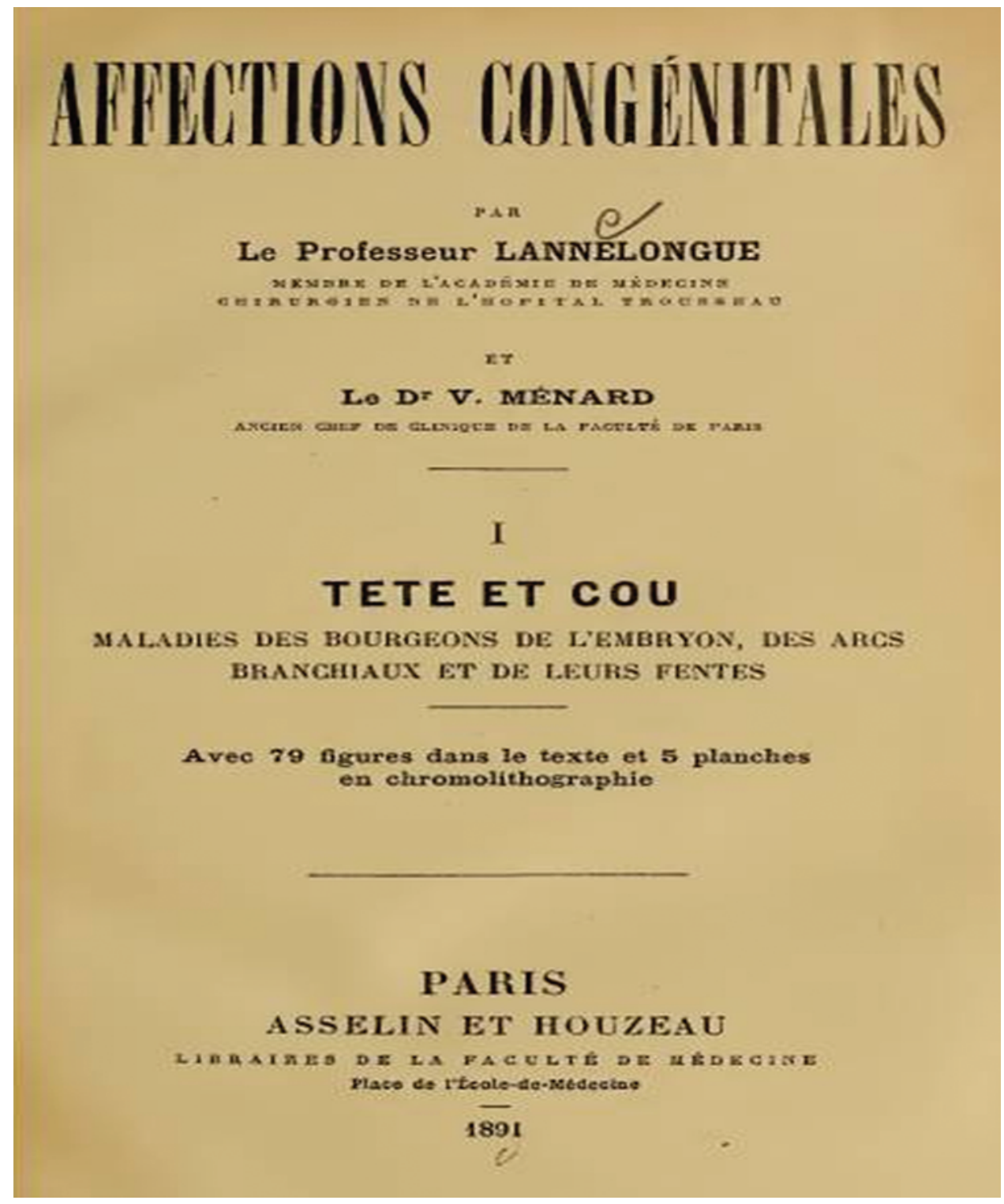

FIG. 2. A page from the book Affections Congénitales published by Dr. Lannelongue and Dr. Menard in 1891.

and of the French Society of Pediatrics. In addition, he was elected as president of the French Academy of Medicine in 1911. Numerous foundations were established in France that bear his name, including a museum in his hometown. ${ }^{12,16}$

\section{Charitable Works}

Dr. Lannelongue was a very generous and kind person. Along with his wife, Mary Lannelongue, he supported several different charities in his hometown and in Paris. He donated $£ 28,000$ to the Institute for Young Girls, which was founded at Clichy by Mary Lannelongue. When working as a senator, he worked to solve difficult problems including repopulation and suppression of alcoholism. As a member and president of professional societies, he developed awards, including the International
Medal of Surgery. This award was created for surgeons whose work had advanced the science related to surgical discovery. The first recipient of this award was Sir Victor Horsley in 1911, and this award is still presented today by the French Academy of Surgery. Dr. Lannelongue also founded a prize at the French Academy of Medicine for the widows of doctors, and 1 award each at the Academy of Science and Faculty of Medicine for the assistance of needy students. ${ }^{12,16}$

\section{Conclusions}

This paper describes the legacy of Dr. Lannelongue and the history behind the strip craniectomy for the treatment of craniosynostosis. His contributions have helped to develop the modern technique of endoscopic strip craniectomies. Dr. Lannelongue was a man of humble man- 


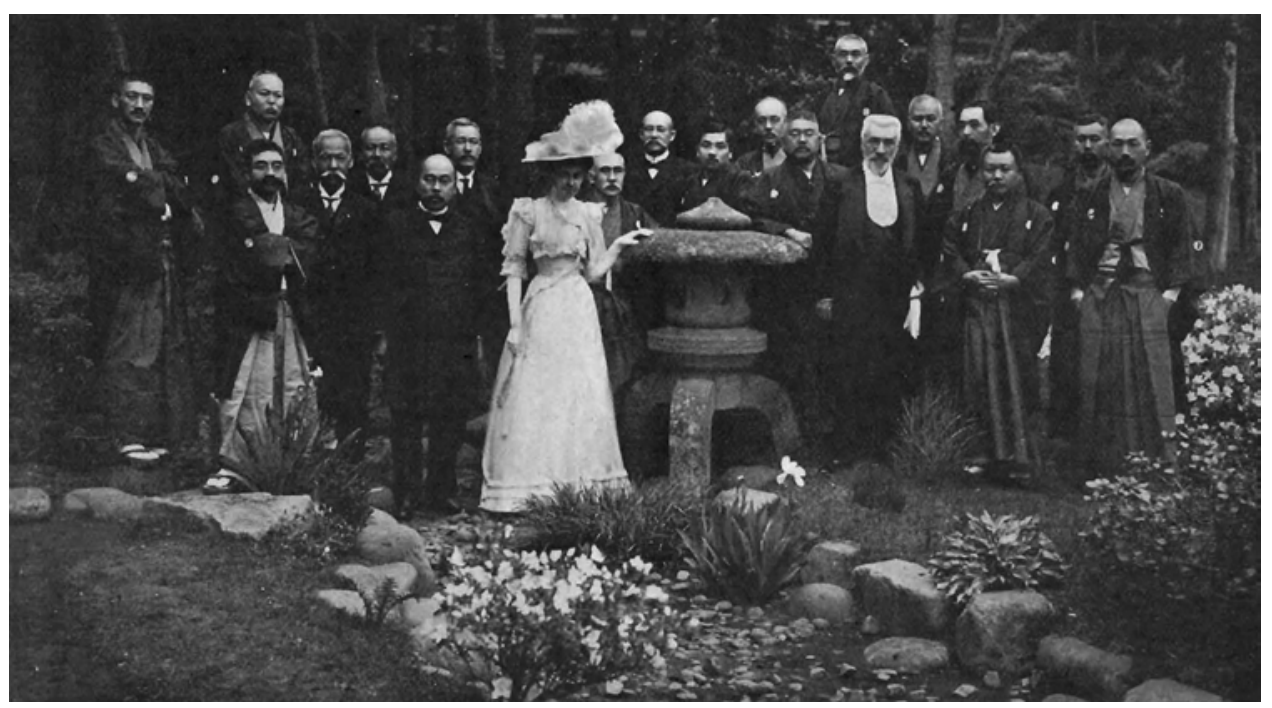

FIG. 3. Dr. Lannelongue with his niece at the University of Tokyo during his world tour.

ners who became the leader in his profession through his hard work. He should be recognized in the field of neurosurgery for his contributions to the surgical treatment of craniosynostosis.

\section{Disclosure}

The authors report no conflict of interest concerning the materials or methods used in this study or the findings specified in this paper.

Author contributions to the study and manuscript preparation include the following. Conception and design: Bir. Drafting the article: Bir. Critically revising the article: all authors. Reviewed submitted version of manuscript: all authors. Approved the final version of the manuscript on behalf of all authors: Nanda.

\section{References}

1. Aleck K: Craniosynostosis syndromes in the genomic era. Semin Pediatr Neurol 11:256-261, 2004

2. Alvarez-Garijo JA, Cavadas PC, Vila MM, Alvarez-Llanas A: Sagittal synostosis: results of surgical treatment in 210 patients. Childs Nerv Syst 17:64-68, 2001

3. Blount JP, Louis RG Jr, Tubbs RS, Grant JH: Pansynostosis: a review. Childs Nerv Syst 23:1103-1109, 2007

4. Boulos PT, Lin KY, Jane JA Jr, Jane JA Sr: Correction of sagittal synostosis using a modified Pi method. Clin Plast Surg 31: 489-498, vii, 2004

5. Cohen MM: Craniosynostosis: Diagnosis, Evaluation, and Management. New York: Raven Press, 1986

6. Death of Professor Lannelongue. JAMA 58:208, 1912

7. Frassanito P, Di Rocco C: Depicting cranial sutures: a travel into the history. Childs Nerv Syst 27:1181-1183, 2011

8. Hunter AG, Rudd NL: Craniosynostosis. I. Sagittal synostosis: its genetics and associated clinical findings in 214 patients who lacked involvement of the coronal suture(s). Teratology 14: 185-193, 1976

9. Jimenez DF, Barone CM: Endoscopic craniectomy for early surgical correction of sagittal craniosynostosis. J Neurosurg 88:77-81, 1998

10. Johnston SA: Calvarial vault remodeling for sagittal synostosis. AORN J 74:632-647, 2001

11. Kapp-Simon KA, Speltz ML, Cunningham ML, Patel PK, To- mita T: Neurodevelopment of children with single suture craniosynostosis: a review. Childs Nerv Syst 23:269-281, 2007

12. Lannelongue M: De la craniectomie dans la microcéphalie. Compt Rend Seances Acad Sci 50:1382-1385, 1890

13. McCarthy JG, Glasberg SB, Cutting CB, Epstein FJ, Grayson $\mathrm{BH}$, Ruff G, et al: Twenty-year experience with early surgery for craniosynostosis: I. Isolated craniofacial synostosis-results and unsolved problems. Plast Reconstr Surg 96:272283, 1995

14. Mehta VA, Bettegowda C, Jallo GI, Ahn ES: The evolution of surgical management for craniosynostosis. Neurosurg Focus 29(6):E5, 2010

15. Murad GJ, Clayman M, Seagle MB, White S, Perkins LA, Pincus DW: Endoscopic-assisted repair of craniosynostosis. Neurosurg Focus 19(6):E6, 2005

16. Obituary: Odilon Marc Lannelongue, M.D.. Professor of Surgical Pathology, University of Paris. BMJ 1:164, 1912

17. Panchal J, Marsh JL, Park TS, Kaufman B, Pilgram T, Huang SH: Sagittal craniosynostosis outcome assessment for two methods and timings of intervention. Plast Reconstr Surg 103:1574-1584, 1999

18. Shillito J Jr, Matson DD: Craniosynostosis: a review of 519 surgical patients. Pediatrics 41:829-853, 1968

19. Slater BJ, Lenton KA, Kwan MD, Gupta DM, Wan DC, Longaker MT: Cranial sutures: a brief review. Plast Reconstr Surg 121:170e-178e, 2008

20. Speltz ML, Kapp-Simon KA, Cunningham M, Marsh J, Dawson G: Single-suture craniosynostosis: a review of neurobehavioral research and theory. J Pediatr Psychol 29:651-668, 2004

21. Venes JL, Sayers MP: Sagittal synostectomy. Technical note. J Neurosurg 44:390-392, 1976

22. Vollmer DG, Jane JA, Park TS, Persing JA: Variants of sagittal synostosis: strategies for surgical correction. J Neurosurg 61: 557-562, 1984

Manuscript submitted December 14, 2013.

Accepted February 17, 2014.

Please include this information when citing this paper: DOI: 10.3171/2014.2.FOCUS13559.

Address correspondence to: Anil Nanda, M.D., Department of Neurosurgery, LSU Health-Shreveport, 1501 Kings Hwy., Shreveport, LA 71130-3932. email: ananda@1suhsc.edu. 